\title{
MODEL SUPERVISI KLINIS PENGAWAS DAN MGMP BAHASA SUNDA UNTUK MENINGKATKAN KOMPETENSI GURU BAHASA SUNDA DALAM MERENCANAKAN PEMBELAJARAN
}

\author{
Haryadi Pramudita \\ SMP Negeri 1 Ciledug Cirebon \\ Email : dita-sunda@yahoo.com
}

\begin{abstract}
Abstrak
Penelitian dipusatkan pada Model Supervisi Klinis oleh Pengawas dan MGMP Bahasa Sunda terhadap guru-guru bahasa Sunda yang ada di Kabupaten Cirebon pada Tahun Ajaran 2011-2012 dengan tujuan untuk mengidentifikasi, mendeskripsikan dan menganalisis pengaruh supervisi klinis oleh Pengawas dan MGMP bahasa Sunda. Metode yang dipakai adalah metode kuasi eksperimen dengan pendekatan kualitatif dengan rancangan desain one group time series design. Instrumen untuk mengukur hasilnya adalah validasi RPP. Lokasi dan sampel penelitian adalah guru-guru yang ada dikabupaten Cirebon berjumlah 35 orang. Hasil penelitian dapat disimpulkan bahwa korelasi antara variabel $\mathrm{X}_{1}$ dan variabel $\mathrm{Y}$ korélasinya positif dan signifikan. Oleh sebab itu, adanya pengaruh supervisi klinis pangawas mata pelajaran bahasa Sunda kepada kompeténsi guru bahasa Sunda dalam membuat RPP sebesar 57,43\%, dan sisa 42,57\% dipengaruhi oleh faktor lainnya. Supervisi Klinis ti Pengawas Mata Pelajaran sanagt stratégis dalam membantu guru baik secara kompeténsi profésional, pédagogik, kapribadian, dan sosial, melalui wadah MGMP.
\end{abstract}

Kata Kunci: supervisi klinis, kompetensi guru, rencana pembelajaran

\section{CLINICAL SUPERVISION MODEL OF SUNDANESE TEACHERS CONSULTATION AND SUPERVISORS TO ENHANCE SUNDANESE TEACHERS' COMPETENCE IN PLANNING INSTRUCTION}

\begin{abstract}
The research focused on the clinical supervision model by Sundanese Teachers Consultation and supervisors implemented to Sundanese teachers in Cirebon regency in 2011-2012 school year. The goal was to identify, describe and analyze the influence of clinical supervision by the Sundanese Teachers Consultation and supervisors. The method used was quasi-experimental, employing a qualitative approach using a one group time series design. The instrument used to measure results was validation of instructional planning. The subjects were 35 teachers at Cirebon regency. Results indicate that the correlation between X1 and Y variables was positive and significant. Therefore, there was $57.43 \%$ influence of the clinical supervision model to Sundanese teachers' competence in designing instructional planning, the remaining $42.57 \%$ was due to other factors. The clinical supervision model successfully aided teachers in their professional competence, pedagogic competence, personality, and social competence within the Teachers Consultation.
\end{abstract}

Keywords: clinical supervision, teachers' competence, instructional planning 


\section{PENDAHULUAN}

Pengembangan sumber daya manusia pendidik, khususnya pengembangan profesional guru, merupakan usaha mempersiapkan guru agar memiliki berbagai wawasan, pengetahuan, keterampilan, dan memberikan rasa percaya diri untuk melaksaakan tugas dan kewajibannya sebagai petugas profesional. Pengembangan atau peningkatan kemampuan profesional harus bertolak pada kebutuhan atau permasalahan nyata yang dihadapi oleh guru, agar bermakna. Undang-undang Republik Indonesia Nomor 14 Tahun 2005 tentang Guru dan Dosen pasal 20 ayat (b) mengamanatkan bahwa dalam rangka melaksanakan tugas keprofesionalannya, guru berkewajiban meningkatkan dan mengembangkan kualifikasi akademik dan kompetensi secara berkelanjutan sejalan dengan perkembangan ilmu pengetahuan, teknologi, dan seni. Pernyataan undang-undang di atas pada intinya mempersyaratkan guru untuk memiliki: (i) kualifikasi akademik minimum S1 atau D-IV; (ii) kompetensi sebagai agen pembelajaran yaitu kompetensi pedagogik, kepribadian, sosial, dan profesional; dan (iii) sertifikat pendidik. Undang-undang ini diharapkan memberikan suatu kesempatan yang tepat bagi guru untuk meningkatkan profesionalismenya secara berkelanjutan melalui pelatihan, penelitian, penulisan karya ilmiah, dan kegiatan profesional lainnya. Kegiatan tersebut sangat dimungkinkan dilaksanakan di Musyawarah Guru Mata Pelajaran (MGMP), mengingat wadah ini dijadikan sebagai tempat melakukan pertemuan bagi mata pelajaran sejenis. Berkaitan dengan peran MGMP yang sangat strategis untuk peningkatan kompetensi guru dan kinerja guru, maka pemberdayaan MGMP merupakan hal mendesak yang harus segera dilakukan. Berbagai upaya untuk meningkatkan kinerja guru, antara lain melalui berbagai pelatihan instruktur, peningkatan sarana dan prasarana, dan peningkatan mutu manajemen MGMP. Dengan lebih terstrukturnya kegiatan guru yang dilakukan di MGMP diharapkan dapat diperhitungkan ekuivalensinya dengan satuan kredit semester (sks) bagi guru yang akan melanjutkan ke jenjang S1 atau pemberian angka kredit bagi guru untuk mengajukan kenaikan kepangkatan (lihat Rambu-rambu pengembangan kegiatan KKG dan MGMP, Depdiknas 2009).

Tujuan pendidikan difokuskeun untuk mencapai tujuan tertentu yakni untuk kapentingan diri siswa, masarakat, dan tuntutan lapangan pekerjaan. Proses pendidikan sendiri difokuskan untuk meningkatkan pengetahuan, kemampuan, keahlian, merubah sikap dan mental siswa dalam menghadapi tantangan masa depan yang lebih berat dalam kehidupan masyrakat. Sebab ada anggapan dari masyarakat bahwa gagalnya pendidikan ada pada pundak guru sebagai ujung tombak pendidikan, hal ini dapat terlihat masih banyaknya tawuran antar pelajar, kemerosotan moral, korupsi dan lainlain.

Guru profésional harus mampu menunjukan citra dan contoh bagi masyarakat, sebab segala perilaku, ucapan, penampilan akan dapat dilihat dan menjadi pusat perhatian hususnya bagi siswa. Kemudian anggapan masarakat akan turunna rata-rata hasil UN dan US kalau dikaitkan dengan keprofésionalan guru di lapangan dimana semuanya dibebankanpada guru. Sabab masih ada guru yang belum mempersiapkan dirinya ketika masuk ke kelas baik buuku, alat dan administrasi sehingga jauh dari tujuan yang diharapkan. Guru juga merupakan faktor yang dominan dalam menentukan keberhasilan dalam pembelajaran. Depdikbud (1994:4) menyatakan "komponen yang mempengaruhi proses belajar mengajar (PBM) adalah siswa, kurikulum, guru, metoda, sarana prasarana dan lingkungan”. Dari tujuh komponén itu, komponén guru sangat menentukan, sabab uru yang akan mengendalikan semua komponen yang lainnya.

Salah satu masalah yang harus dihapai adalah bagaimana peran dan kedudukan guru agar bisa mengikti perkembangan jaman dengan bekal pengetahuan yang terus berkembang sehingga akan menghasilkan kreatifitas menciptakan produk baru atawa hasil modifikasi, stratégi 
pangajaran, bisa menemukan hal-hal baru dalam inovasi pendidikan.

Berdasarkan keterangan di atas, upaya meningkatkan mutu keprofésionalan guru harus terus dikembangkan melalui suatu wadah kegiatan organisasi profési sebagaimana ciri yang disampaikan oleh Natawidjaja (1989) Ada standar kinerja yang baku dan jelas Adanya lembaga atikan yang khusus Adanya organisasi profési yang mewadahi Adanya étika dan kode etik yang mengatur Adanya sistem imbalan terhadap jasa layanannya yang adil dan baku

Adanya pengakuan dari masarakat

Kondisi mengajarkan bahasa Sunda di Kabupaten Cirebon mempunyai tantangan yang unik dan berat bagi sebagian guru, hal ini karena siswa di Kabupaten Cirebon bahasa sehariharinya adalah bahasa Cirebon, sedangkan jumlah sekolah SMP negeri dan swasta 140 sekolah. Dari 140 sekolah tersebut guru bahasa Sunda yang sesuai dengan latar belakang pendidikan bahasa Sunda 12 orang jauh dari harapan, sedangkan sisanya yang 128 sekolah diajar oleh bukan guru bahasa Sunda. Kendala lainnya adalah minimnya sarana dan prasarana baik buku maupun media pembelajaran bahasa Sunda guna menunjang keterlaksanaan pembelajaran, minimnya pengetahuan guru, serta pelatihan dan kegiatan yang menunjang untuk peningkatan keprofesian guru.

Berdasarkan temuan masalah-masalah di atas, penelitian tentang "Model Supervisi Klinis Pengawas dan MGMP Bahasa Sunda untuk meningkatkan Kompetensi Guru Bahasa Sunda dalam menyusun rencana pembelajaran perlu dilaksanakan.

Penelitian ini bertujuan untuk menjawab berbagai pertanyaan hususnya untuk mengidentifikasi, mendeskripsikeun dan menganalisis pangaruh supervisi klinis oleh Pengawas dan MGMP bahasa Sunda terhadap peningkatkan kompetensi Guru Bahasa Sunda di Kabupaten Cirebon dalam merencanakan pembelajaran.

\section{METODE}

Penelitian ini dilaksanakan terhadap guruguru yang ada di Kabupaten Cirebon berjumlah 35 orang pada tahun ajaran 2011-2012. Desain dalam penelitian ini dipake one group time series design, yaitu desain yang tidak memakai kelompok pembanding. Kelompok eksperimen hanya guru yang dibimbing dengan teknik supervisi klinis melalui Kegiatan MGMP tanpa membedakan status sekolah dan wilayah. Metode yang digunakan dalam penelitian ini yaitu metode kuasi eksperimen dengan pendekatan kualitatif dengan tujuan mendapatkan data yang akurat tentang informasi gambaran objek penelitian. Cara pengolahan data dan informasi disebut metode deskriptif analisis.

Data dikumpulkan dengan teknik tes. Instrumen yang digunakan lembaran tes pembuatan RPP dan validasi RPP. Dimana lembar validasi RPP yang digunakan berupa daftar (check list), pernyataaan yang harus diisi oleh validator.

\section{HASIL DAN PEMBAHASAN}

Sebelum ditelaah dan dianalisis data yang ada tentu harus dijelaskan bahwa kegiatan ini dilaksanakan oleh MGMP Bahasa Sunda selama sepuluh kali pertemuan yang diikuti oleh 80 orang guru. Kegiatan supervisi klinis sendiri dilaksanakeun bersamaan dengan kegiatan pelatihan guru-guru yang dilaksanakeun oleh MGMP Bahasa Sunda dalam kurun waktu dari Oktober 2011 sampai dengan bulan Januari 2012. Kegiatan supervisi klinisna dibagi dua tahap yaitu bimbingan langsung sacara teknis dalam waktu kegiatan dan kunjungan langsung ka sakolah oleh pengawas dalam waktu yang beda. Adapun teknis pelaksanaannya jumlah guru yang menjadi peserta kegiatan MGMP dikelompokakan berdasarkan pendidikan, ruang lingkup sekolah dan proporsi kawilayahan. Jumlah guru sebagai peserta kegiatan MGMP Bahasa Sunda yaitu 80 guru yang aktif dari 140 sekolah yang ada di Cirebon. Guru yang dibimbing dalam kegiatan supervisi klinis oleh pengawas 35 guru berdasarkan latar belakang pendidikan serta wilayah. Dalam pra 
kegiatan guru diberi kuisioner apa keluhan dalam menyusun rencana pembelajaran. Hasil kuisioner tersebut akan dipilah-pilah berdasarkan kebutuhan guru dalam melaksanakan dan membuat perencanaan pembelajaran. Dalam Kegiatan pre test guru diberi tugas menyusun satu RPP.

Berdasarkan data hasil pos tes bahwa guru ada peningkatan kemampuan dalam menyusun RPP yang menjadi bahan menyusunan kelompok berdasrkan hasil dari angket yang telah diisi oleh guru sehingga memudahkan pembagian kelompok berdasarkan komponen RPP apakah dari segi tujuan, materi atawa evaluasi. Dari 8 komponen yang diujikeun, rata-rata guru lemah dalam menentukan tujuan serta evaluasi. Oleh karena itu materi kegiatan MGMP membahas tentang bagaimana menentukan tujuan dan evaluasi pembelajaran.

Kelemahan lainnya dalam menentukan materi kegiatan yang sesuai dengan tuntutan kurikulum. Karena siswanya berlatarbelakang bahasa Cirebon maka guru harus mencari materi bahasa Sunda yang tidak terlalu sulit serta sesuai kemampuan siswa tersebut. Sedangkan berdasarkan hasil penelitian perkara pengaruh supervisi klinis pangawas mata pelajaran bahasa Sunda dan kegiatan MGMP bahasa Sunda terhadap kompeténsi guru bahasa Sunda di Kabupatén Cirebon dalam merencanakan pembelajaran, bisa diuraikan sebagai berikut.

Berdasarkan hasil perhitungan di atas, korelasi antara variabel $\mathrm{X}_{1}$ dan variabel $\mathrm{Y}$ didapat $r=0,758$. Dipatalikeun dengan kriteria penafsiran Arikunto (2003:260), harga $r=0,758$ ada di antara 0,600 - 0,800, artinya hubungannya cukup. Hal ini menunjukkan bahwa hubungan antara Supervisi Klinis Pangawas Bahasa Sunda dan Kompetensi Guru Bahasa Sunda dalam merencanakan pembelajaran cukup. Tapi berdasarkan perhitungan uji-t dicapai nilai $\mathrm{t}_{\text {hitung }}=6,673$ lebih tinggi daripada $\mathrm{t}_{\text {tabél }}=1,690$ berdasarkan tingkat kepercayaan $95 \%$ dengan nilai $n=30(6,673>1,690)$. Dengan data ini menunjukkan bahwa ada korélasi yang positif dan signifikan antara variabel $\mathrm{X}_{1}$ dan $\mathrm{Y}$.

Untuk menentukan berapa besaran pengaruh variabel Supervisi Klinis Pangawas Mata Pelajaran Bahasa Sunda $\left(X_{1}\right)$ terhadap Kompeténsi Guru Bahasa Sunda di Kabupatén Cirebon dalam merencanakan (Y), dapat dilihat dari koéfisién déterminasina yang mencapai angka 57,43\%. Hal menunjukkan bahwa pengaruh supervisi klinis pangawas mata pelajaran bahasa Sunda terhadap kompeténsi guru Bahasa Sunda dalam merencanakan sebesar $57,43 \%$, dan sisanya sebesar $42,57 \%$ dipengaruhi oleh faktor lainnya.

Untuk menentukan prédiksi naiknya nilai variabel $Y$ ketika variabel $\mathrm{X}_{1}$ naik, digunakan perhitungan analisis régrési liniér sederhana. Berdasarkan hasil perhitungan analisis régrési liniér sederhana variabel $\mathrm{X}_{1}$, dicapai persamaan: $\mathrm{Y}=28,76+0,54 \mathrm{X}$. Hal ini menunjukkan bahwa nilai supervisi klinis pangawas mata pelajaran bahasa Sunda bertambah 1 yang menyebabkan nilai kompeténsi guru bahasa Sunda dalam merencanakan pembelajaran bertambah menjadi 0,54 .

Untuk variabel $\mathrm{X}_{2}$, berdasarkan hasil perhitungan korelasi antara variabel $\mathrm{X}_{2}$ dengan variabel $\mathrm{Y}$ dicapai $\mathrm{r}=0,754$. Kalau dikaitkan dengan kriteria penafsiran Arikunto (2003:260), harga $r=0,754$ ada di antara 0,600 - 0,800, yang berarti hubungannya cukup. Hal ini menunjukkan hubungan antara Kegiatan MGMP Bahasa Sunda dengan Kompetensi Guru Bahasa Sunda dalam merencanakan pembelajaran cukup. Sedangkan berdasarkan perhitungan uji-t dicapai nilai $t_{\text {hitung }}=6,588$ lebih tinggi daripada $\mathrm{t}_{\text {tabél }}=1,690$ berdasarkan tingkat kepercayaan $95 \%$ dengan nilai $\mathrm{n}=30(6,673>$ 1,675). Oleh karena itu ada korélasi yang positif dan signifikan antara variabel $\mathrm{X}_{2}$ danY.

Untuk menentukan besaran pengaruh variabel Kegiatan MGMP Bahasa Sunda $\left(\mathrm{X}_{2}\right)$ terhadap Kompeténsi Guru Bahasa Sunda di Kabupatén Cirebon dalam merencanakan pembelajaran (Y), dapat dilihat dari koéfisién déterminasinya yaitu nilai $56,81 \%$. Harga koefisien diterminan di atas menggambarkan bahwa variabel $\mathrm{X}_{2}$ dapat menjelaskan variasi yang ada dalam variabel $\mathrm{Y}$ dengan daya prediksi sebesar $56,81 \%$. Hal ini berarti, 
pengaruh Kegiatan MGMP Bahasa Sunda terhadap Kompetensi Guru Bahasa Sunda dalam merencanakan pembelajaran cukup tinggi yaitu $56,81 \%$ dan sisanya $43,19 \%$ dipengaruhi oleh faktor liannya.

Untuk menentukan prédiksi naiknya nilai variabel $Y$ ketika variabel $\mathrm{X}_{2}$ naik, digunakan perhitungan analisis régrési liniér sederhana. Berdasarkan hasil perhitungan analisis régrési liniér sederhana variabel $\mathrm{X}_{2}$, dicapai persamaan: $\mathrm{Y}=32,51+0,49 \mathrm{X}$. Hal ini menunjukkan bahwa nilai Kegiatan MGMP Bahasa Sunda bertambah 1 yang menyebabkan nilai kompeténsi guru Bahasa Sunda dalam merencanakan pembelajaran bertambah menjadi 0,49 .

Selain adanya korélasi yang signifikan antara $X_{1}$ dan $Y$ serta $X_{2}$ dan $Y$, secara bersamaan $\mathrm{X}_{1}$ dan $\mathrm{X}_{2}$ mempengaruhi terhadap $\mathrm{Y}$. Korelasi ganda antara variabel $\mathrm{X}_{1}$ dan $\mathrm{X}_{2}$ secara bersama terhadap variabel $\mathrm{Y}$ dicapai $R=0,7404$. Kalau dikaitkan dengan kriteria penafsiran Arikunto (2003:260), harga $\mathrm{R}$ yang 0,7404 ada di antara 0,600 - 0,800, yang berarti memiliki hubungan yang cukup. Oleh karena itu hubungan antara Supervisi Klinis Pangawas Mata Pelajaran Bahasa Sunda dengan Kegiatan MGMP Bahasa Sunda secara bersamaan memiliki hubungan yang cukup dengan Kompetensi Guru Bahasa Sunda dalam merencanakan pembelajaran.

\section{SIMPULAN}

Supervisi Klinis Pengawas Mata Pelajaran sebagai kegiatan yang stratégis dalam memberikan bantuan meningkatkan kompeténsi guru, baik kompeténsi profésional, pédagogik, kapribadian, maupun sosial. Guru bahasa Sunda dituntut mampuh dalam merencanakan, melaksanakan dan evaluasi pembelajaran dengan berbagai sarana, baik formal maupun informal.

Penelitian ini menyimpulkan bahwa terdapat hubungan antara Supervisi Klinis Pangawas Mata Pelajaran Bahasa Sunda dengan Kegiatan MGMP Bahasa Sunda terhadap Kompeténsi Guru Bahasa Sunda dalam merencanakan pembelajaran, baik secara individu maupun kelompok ada korélasina yang signifikan.

\section{PUSTAKA RUJUKAN}

Departemen Pendidikan Nasional. 2009. Panduan Supervisi Klinis dan Evaluasi Pelaksanaan KTSP. Jakarta: Direktorat Pembinaan SMP.

Natawidjaja, Rochman. 2002. Profesionalisasi Tenaga Kependidikan. Bandung: Program Pascasarjana UPI.

Undang-Undang RI. No. 14 Tahun 2005 tentang Guru dan Dosen.

\section{UCAPAN TERIMA KASIH}

Terima kasih dan penghargaan setinggitingginya penulis sampaikan kepada semua pihak yang telah membantu sehingga artikel ini dapat dimuat. Ucapan terima kasih disampaikan kepada Kepala SMP Negeri 1 Ciledug Cirebon, Ketua Prodi Pendidikan Bahasa dan Budaya Sunda SPs UPI, dosen di Program Studi Pendidikan Bahasa dan Budaya Sunda SPs UPI, rekan sejawat, dan rekan mahasiswa. 